08

\title{
Влияние однородных магнитного и электрического полей на микроструктурные и субструктурные характеристики продуктов сгорания нанопорошка алюминия в воздухе
}

\author{
(С) А.П. Ильин, А.В. Мостовщиков, А.Я. Пак
}

Томский политехнический университет, 634050 Томск, Россия

e-mail: pasembellum@mail.ru

(Поступило в Редакцию 13 июля 2015 г.)

Исследовано влияние постоянных электрического и магнитного полей на микро- и субструктурные характеристики продуктов сгорания нанопорошка алюминия в воздухе. Установлено, что при сгорании нанопорошка алюминия в магнитном поле формируются монокристаллы гексагонального габитуса, а при сгорании в электрическом поле формируются ограненные кристаллиты слоистой морфологии. Поля оказывают заметное влияние на параметры кристаллической решетки оксида и нитрида алюминия: они снижают размеры областей когерентного рассеяния в нитриде алюминия, и повышают их в $\gamma$-оксиде алюминия. В то же время смещение атомов относительно положения равновесия уменьшилось для всех кристаллических фаз при действии полей, за исключением нитрида алюминия в магнитном поле. Полученные результаты объясняются ориентирующим и стабилизирующим действием полей на продукты сгорания нанопорошка алюминия в воздухе.

\section{Введение}

Ранее считалось $[1,2]$, что при сгорании порошкообразных металлов в воздухе конечными продуктами сгорания являются оксиды этих металлов. В работах $[3,4]$ было установлено, что в конечных продуктах сгорания нанопорошка алюминия и его смесей с оксидами стабилизируются соответствующие нитриды, что не согласуется с данными термодинамических расчетов [5]. При нагревании нанопорошка алюминия (НП) в газообразном азоте образуется нитрид алюминия, при этом сферическая форма частиц сохраняется [6]. Энтальпия образования AlN составляет $-320 \mathrm{~kJ} / \mathrm{mol}$, что в 2.5 раза меньше энтальпии образования $\gamma$-оксида алюминия $(-837 \mathrm{~kJ} / \mathrm{mol})$, поэтому взаимодействие алюминия с азотом при нагревании протекает в диффузионном режиме, а с воздухом - в режиме теплового взрыва [7]. Формирование нитрида алюминия снижает характеристики высокоэнергетических материалов [8], а форма и размеры продуктов сгорания определяют двухфазные потери твердых топлив. Процесс фазообразования протекает самопроизвольно с участием кислорода и азота воздуха. Температура продуктов горения достигает $2200-2400^{\circ} \mathrm{C}$, и наряду с диффузионными процессами окисления и фазообразования протекают процессы испарения-конденсации с образованием нитевидных кристаллов (вискеров) AlN. B процессе горения нанопорошка алюминия наблюдались колебательные процессы (температура-скорость), сопровождающиеся формированием двухуровневых нитевидных кристаллов. Известно, что электрическое и магнитное поля влияют на структурные характеристики продуктов самораспространяющегося высокотемпературного синтеза $[9,10]$. В то же время практически не изучено влияние полей на микроструктурные и субструктурные характеристики продуктов сгорания порошкообразного алюминия [11].

Целью работы являлось установление закономерностей влияния постоянных электрического и магнитного полей на микроструктурные и субструктурные характеристики продуктов сгорания нанопорошка алюминия в воздухе.

\section{Экспериментальные результаты}

Для исследования влияния воздействия постоянных магнитного и электрического полей на структуру конечных продуктов сгорания нанопорошка алюминия проводили сжигание образцов в алундовых тиглях. В тигли помещали навеску нанопорошка алюминия (по $3 \mathrm{~g}$ ) без уплотнения, один тигель помещали на дюралюминиевой пластине в поле постоянного магнита (индукция поля $0.34 \mathrm{~T})$, другой тигель помещали только на дюралюминиевую пластину, третий тигель помещали в постоянное электрическое поле плоского воздушного конденсатора (напряженность поля $10 \mathrm{kV} / \mathrm{m}$ ). Горение инициировали с помощью нагретой электрическим током нихромовой спирали, во всех тиглях процесс протекал в режиме свободного доступа воздуха. После сгорания и охлаждения тиглей продукты синтеза дезагрегировали и просеивали через сито с размерами ячеек $63 \mu \mathrm{m}$. Рентгеноструктурные исследования образцов продуктов сгорания проводили с использованием дифрактометра Shimadzu XRD $7000\left(\mathrm{Cu} K_{\alpha}\right.$-излучение, графитовый монохроматор излучения Shimadzu CM-3121).

Ранее было установлено, что основными кристаллическими фазами продуктов сгорания нанопорошка 
алюминия в воздухе являются $\mathrm{AlN}, \gamma-\mathrm{Al}_{2} \mathrm{O}_{3}, \mathrm{Al}_{5} \mathrm{O}_{6} \mathrm{~N}$ и несгоревший алюминий [12].

При сгорании нанопорошка алюминия в тигле происходило формирование неограненных кристаллитов с размерами до 5-8 $\mu \mathrm{m}$ (рис. 1).

При сгорании нанопорошка алюминия в однородном постоянном магнитном поле в алундовом тигле происходило формирование монокристаллов нитрида алюминия гексагонального габитуса с хорошим огранением и характерными размерами $2-4 \mu \mathrm{m}$ (рис. 2).

На рис. 3 представлена микрофотография образца (общий вид), сожженного в алундовом тигле на расположенной горизонтально пластине, подключенной к электроду с отрицательным электрическим потенциалом.

На микрофотографии (рис. 3) видна микроструктура продуктов сгорания: поверхность образована пластинами (видны ступени роста), что свидетельствует о ступенчато-слоистом росте кристаллов в данных условиях.

Анализ данных рентгенофазового анализа продуктов сгорания нанопорошка алюминия показал, что содержание нитрида алюминия максимально при формировании продуктов сгорания в магнитном поле, затем - в электрическом поле. Минимальное содержание нитрида алюминия обнаружено в продуктах сгорания нанопорошка алюминия в тигле без воздействия полей. Необходимо отметить, что, согласно рентгеноструктурному анализу, структура фазы $\mathrm{AlN}$, сформировавшейся при горении нанопорошка алюминия в тигле в магнитном поле, отличается от структуры этой фазы, сформировавшейся в других условиях: интенсивность дифракционного максимума от плоскости $(10 \overline{1} 0)$ нитрида алюминия возросла в 1.1 раза (увеличилась на 10\%).

Математический расчет параметров кристаллической структуры продуктов сгорания нанопорошка алюминия в воздухе без воздействия поля, в магнитном поле и в электрическом поле проводили с использованием программного пакета PowderCell 2.4 с использованием структурных параметров из карточек эталонных образцов сравнения базы PDF2+. Результаты рентгеноструктурного анализа приведены в таблице.

Согласно полученным результатам (таблица), образовавшийся в процессе горения $\mathrm{AlN}$ имел расчетные значения параметров решетки, различающиеся с эталоном в 4-м знаке после запятой. Нитрид алюминия характеризовался размерами ОКР примерно $119 \mathrm{~nm}$ и смещением атомов относительно положения равновесия $1.9 \cdot 10^{-3}$. Фаза нитрида алюминия, сформированная в магнитном поле, характеризовалась уменьшением параметра $a$ на $0.01 \%$ и параметра $c$ на $0.05 \%$. В то же время область когерентного рассеяния уменьшилась на $32 \%$, и наблюдалось небольшое увеличение смещения атомов относительно положения равновесия. Таким образом, воздействие магнитного поля на формирующуюся фазу AIN привело к увеличению механической напряженности решетки: параметры решетки уменьшились, что подтверждается уменьшением величины ОКР и увеличением смещения атомов относительно положения равновесия.

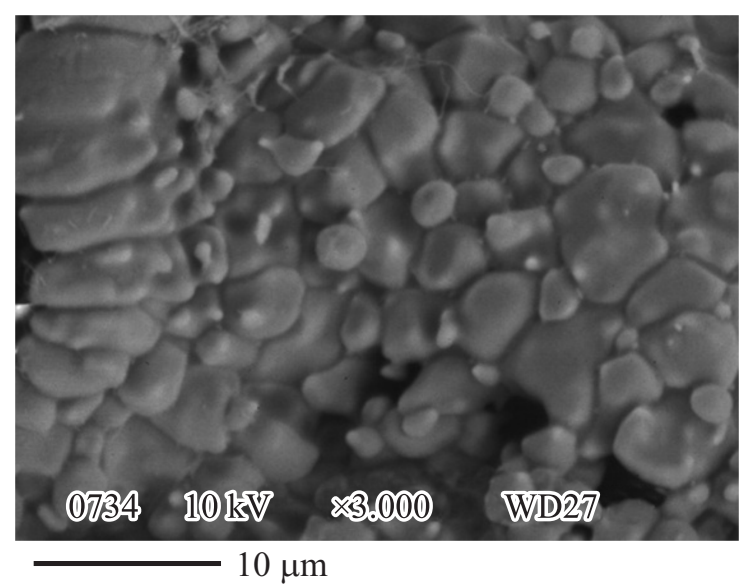

Рис. 1. Микрофотография продуктов сгорания нанопорошка алюминия в алундовом тигле в воздухе.

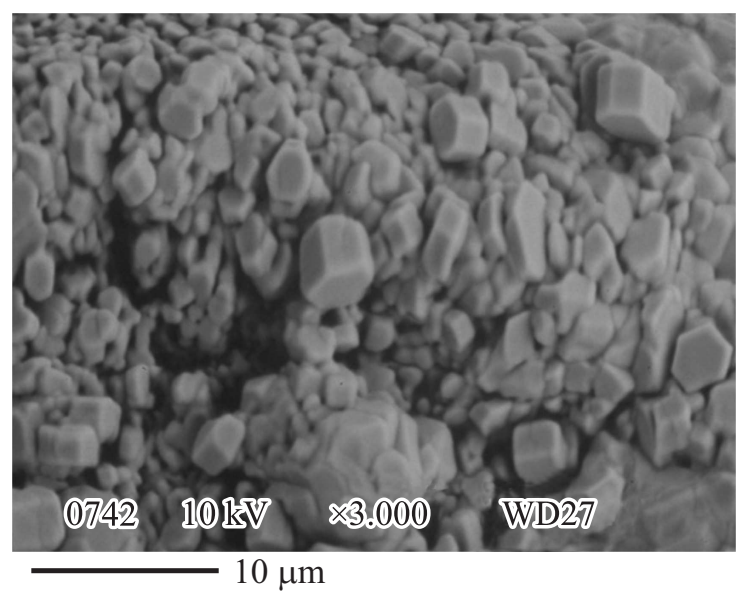

Рис. 2. Микрофотография продуктов сгорания нанопорошка алюминия в алундовом тигле при воздействии однородного постоянного магнитного поля.

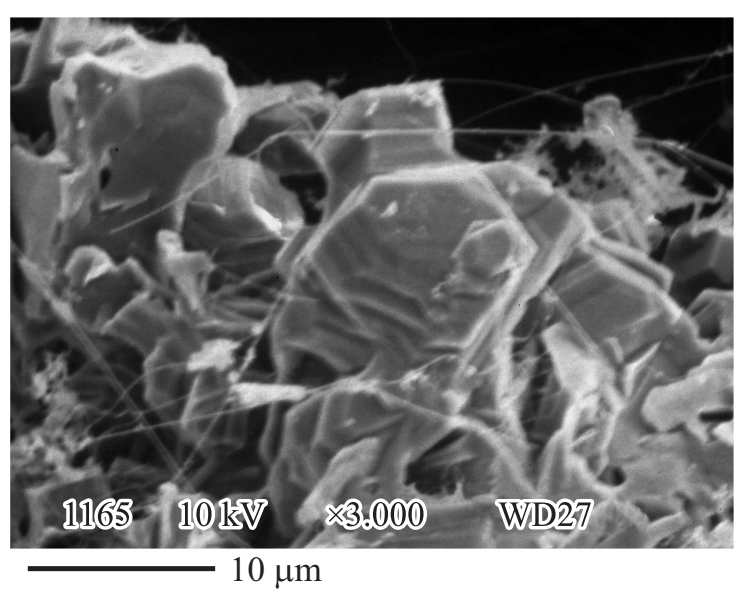

Pис. 3. Микрофотография продуктов сгорания нанопорошка алюминия в воздухе в алундовом тигле, установленном на электроде с отрицательным электрическим потенциалом. 
Результаты рентгеноструктурного анализа продуктов сгорания нанопорошка алюминия

\begin{tabular}{|c|c|c|c|c|c|}
\hline \multirow{2}{*}{ Фаза } & \multirow{2}{*}{ Вид воздействия } & \multicolumn{2}{|c|}{ Параметр решетки, nm } & \multirow{2}{*}{$\begin{array}{c}\text { Область } \\
\text { когерентного } \\
\text { рассеяния } \\
\left(d_{\mathrm{csr}}\right), \mathrm{nm}\end{array}$} & \multirow{2}{*}{$\begin{array}{c}\text { Смещение атомов } \\
\text { относительно } \\
\text { положения равновесия } \\
\frac{\Delta d}{d} 10^{-3}\end{array}$} \\
\hline & & рассчитанный & эталон & & \\
\hline \multirow{3}{*}{$\mathrm{AlN}$} & Без поля & $\begin{array}{l}a=0.31126 \\
c=0.49781\end{array}$ & \multirow{3}{*}{$\begin{array}{l}a=0.3113 \\
c=0.4981\end{array}$} & 119 & 1.90 \\
\hline & Магнитное поле & $\begin{array}{l}a=0.31124 \\
c=0.49775\end{array}$ & & 80 & 1.95 \\
\hline & Электрическое поле & $\begin{array}{l}a=0.31082 \\
c=0.49666\end{array}$ & & 77 & 0.44 \\
\hline \multirow{3}{*}{$\gamma-\mathrm{Al}_{2} \mathrm{O}_{3}$} & Без поля & $\begin{array}{l}a=0.47962 \\
c=1.29177\end{array}$ & \multirow{3}{*}{$\begin{array}{l}a=0.4761 \\
c=1.2995\end{array}$} & 42 & 1.61 \\
\hline & Магнитное поле & $\begin{array}{l}a=0.47587 \\
c=1.29900\end{array}$ & & 95 & 0.24 \\
\hline & Электрическое поле & $\begin{array}{l}a=0.48005 \\
c=1.28934\end{array}$ & & 70 & 0.61 \\
\hline \multirow{3}{*}{$\mathrm{Al}$} & Без поля & $a=0.40490$ & \multirow{3}{*}{$a=0.4049$} & 96 & 0.64 \\
\hline & Магнитное поле & $\begin{aligned} a & =0.40484 \\
c & =0.40484\end{aligned}$ & & 255 & 1.02 \\
\hline & Электрическое поле & $a=0.40438$ & & 81 & 0.29 \\
\hline
\end{tabular}

Действие электрического поля на фазу AIN неоднозначно: параметры решетки и размеры ОКР уменьшились, но смещение атомов относительно положения равновесия уменьшилось существенно (примерно в 3 раза).

Субструктурные характеристики $\gamma-\mathrm{Al}_{2} \mathrm{O}_{3}$, сформированного в процессе горения без поля, отличаются от эталона только по параметру $c$ (менее $0.59 \%)$. Этот образец характеризуется областью когерентного рассеяния размерами $42 \mathrm{~nm}$ и величиной смещения атомов относительно положения равновесия $1.61 \cdot 10^{-3}$. При формировании фазы $\gamma-\mathrm{Al}_{2} \mathrm{O}_{3}$ в магнитном поле параметры его решетки практически сравнимы с эталоном, но в то же время размеры области когерентного рассеяния увеличились более чем в 2 раза и величина смещения атомов относительно положения равновесия уменьшилась в 6 раз. Следовательно, магнитное поле приводит к стабилизации более стабильной фазы $\gamma-\mathrm{Al}_{2} \mathrm{O}_{3}$, в сравнении с аналогичной фазой, сформированной без воздействия поля.

Действие электрического поля на $\gamma-\mathrm{Al}_{2} \mathrm{O}_{3}$ привело к увеличению параметра $a$ на $0.82 \%$, а по параметру $c-$ к уменьшению на $0.78 \%$. В то же время область когерентного рассеяния увеличилась примерно в 2 раза, а величина смещения атомов также увеличилась в 2.5 раза относительно субструктуры $\gamma-\mathrm{Al}_{2} \mathrm{O}_{3}$, сформированной без поля.

Не сгоревшая фаза алюминия формируется из нанопорошка за счет тепла, выделившегося при горении. Как правило, температура достаточна для спекания нанопо- рошка алюминия в крупные капли, на которые также действовали поля. Согласно данным таблицы, кубическая решетка остаточного алюминия по параметру $a$ не изменялась, фаза алюминия после горения характеризуется областью рассеяния $96 \mathrm{~nm}$ и смещением атомов относительно положения равновесия $0.64 \cdot 10^{-3}$. Остаточный алюминий в магнитном поле характеризуется уменьшенным параметром решетки (на $0.01 \%$ ), и размером области когерентного рассеяния $255 \mathrm{~nm}$ (в 3 раза больше), и увеличенным в 1.5 раза смещением атомов относительно положения равновесия. Действие электрического поля приводит к более существенному уменьшению параметра решетки, но в то же время область когерентного рассеяния в сравнении с образцом без поля уменьшается на $15 \%$, и смещение атомов относительно положения равновесия также уменьшилось в 2 раза.

Следовательно, действие магнитного поля на алюминий приводит к уменьшению параметра решетки, увеличению размера области когерентного рассеяния и величины смещения атомов относительно положения равновесия, что неоднозначно влияет на стабилизацию фазы алюминия, сформировавшейся в магнитном поле. В то же время электрическое поле уменьшало параметр решетки, но мало влияло на величину области когерентного рассеяния и уменьшало величину смещения атомов относительно положения равновесия: действие полей на стабильность кристаллической решетки алюминия (параметры субструктуры) неоднозначно. 


\section{Заключение}

Постоянные магнитное и электрическое поля оказывали заметное влияние на микро- и субструктуру основных продуктов сгорания нанопорошка алюминия в воздухе. Оба поля способствовали кристаллизации продуктов сгорания: в магнитном поле формировались объемные монокристаллы, а в электрическом — плоские кристаллы, образующие друзы.

Более устойчивой структурой является кристаллическая фаза, характеризующаяся максимальным значением размеров области когерентного рассеяния и минимальным смещением атомов относительно положения равновесия - фаза $\gamma-\mathrm{Al}_{2} \mathrm{O}_{3}$, образующаяся при сгорании нанопорошка алюминия в электрическом поле.

Механизм действия полей, предложенный ранее [11], связан со стабилизацией аморфных продуктов сгорания, их переохлаждением и кристаллизацией в тепловой волне. Источник тепловой энергии - запасенная энергия наноструктур, образующихся при горении нанопорошка алюминия. Анализ субструктурных характеристик продуктов сгорания показал, что наиболее устойчивой (стабильной) кристаллической структурой является $\gamma-\mathrm{Al}_{2} \mathrm{O}_{3}$, сформированный в электрическом поле.

Исследования выполнены при финансовой поддержке РФФИ. Грант № 15-03-05385.

\section{Список литературы}

[1] Похил П.Ф., Беляев А.Ф., Фролов Ю.В. и др. Горение порошкообразных металлов в активных средах. М.: Наука, 1972. $294 \mathrm{c}$.

[2] Сарнер С. Химия ракетных топлив. М.: Мир, 1969. 488 с.

[3] Ильин А.П., Проскуровская Л.Т. // Физика горения и взрыва. 1990. Т. 26. Вып. 2. С. 71-74.

[4] Ильин А.П., Проскуровская Л.Т. // Порошковая металлургия. 1990. Вып. 9. С. 32-35.

[5] Боборыкин В.М., Гремячкин В.М., Истратов А.Г. и др. // Физика горения и взрыва. 1983. Вып. 3. С. 22-29.

[6] Коршунов А.В. Размерные и структурные эффекты в процессах окисления металлов. Томск: Изд-во Том. политех. ун-та, 2013. $360 \mathrm{c}$.

[7] Ильин А.П., Громов А.А. Горение алюминия и бора в сверхтонком состоянии. Томск: Изд-во Том. ун-та, 2002. $154 \mathrm{c}$.

[8] Энергетические конденсированные системы. Краткий энциклопедический словарь / Под ред. Б.П. Жукова. М.: Янус К, 2000. 596 с.

[9] Максимов Ю.М., Кирдяшкин А.И., Смоляков В.К., Итин В.И. СВС. Теория и практика. Черноголовка: Территория, 2001. С. 215-235.

[10] Концепция развития СВС как области научно-технического прогресса / Под ред. А.Г. Мержанова. Черноголовка: Территория, 2003. 368 с.

[11] Ильин А.П., Мостовщиков А.В., Роот Л.О. // Письма в ЖТФ. 2011. Т. 37. Вып. 20. С. 49-53.

[12] Ильин А.П., Мостовщиков А.В., Тимченко Н.А. // Физика горения и взрыва. 2013. Т. 49. Вып. 3. С. 72-76. 